\title{
Vegetable Information Release Model for Traceability Fingerprint Vegetable
}

\author{
Zhao Qiang $^{1, a}$, Chang Fenghao ${ }^{2, b}$ \&Peng Minjing ${ }^{3, c}$ \\ ${ }^{1}$ School of Economics and Management, Wuyi University, Jiangmen, Guangdong 529020, China \\ ${ }^{2}$ Engineering Technology Center of E- commerce Augmented Reality of Guangdong Province, \\ Jiangmen, Guangdong 529020, China \\ ${ }^{3}$ Engineering Technology Center of E- commerce Augmented Reality of Guangdong Province, \\ Jiangmen, Guangdong 529020, China

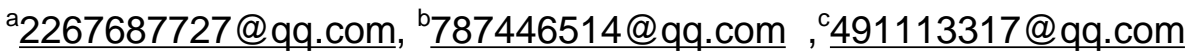

Keywords: Milestone record, Information release, Automatic Summarization of Information

Abstract. The traceability of agricultural products safety is becoming prominent, and consumers do not have a sufficient understanding of vegetable information. This paper summarizes that Vegetable information release system and we have made a milestone record of the growth cycle through the information summary automatic generation technology. Based on these, we propose a model of vegetable information release. People achieve the value of vegetables and purpose of traceability from the Internet platform. Consumer supervision will further strengthen the effective supervision of agricultural product quality, improve the safety of agricultural products and promote the process of agricultural standardization.

\section{Introduction}

Establish traceability system from farmland to the table is the key to ensure the quality and safety of agricultural products, and the protection of farmers to participate in the source of traceability is particularly important ${ }^{[1]}$. Only the establishment of agricultural production records system, to fully record and preserve the quality and safety of agricultural products source of information, can we establish a feasible and efficient agricultural products traceability system. Therefore, the source of agricultural products traceability is the basis of the formation and system construction of agricultural products traceability system, the government and the agricultural industrialization organizations play an important role ${ }^{[2]}$. Farmers, as the implementation of the record, their participation will and participation behavior, will be related to the success of the source tracing. A complete system of agricultural products should be the following points, which is the necessary records of agricultural products and vegetables information release model. Vegetable information release model shows in Fig. 1

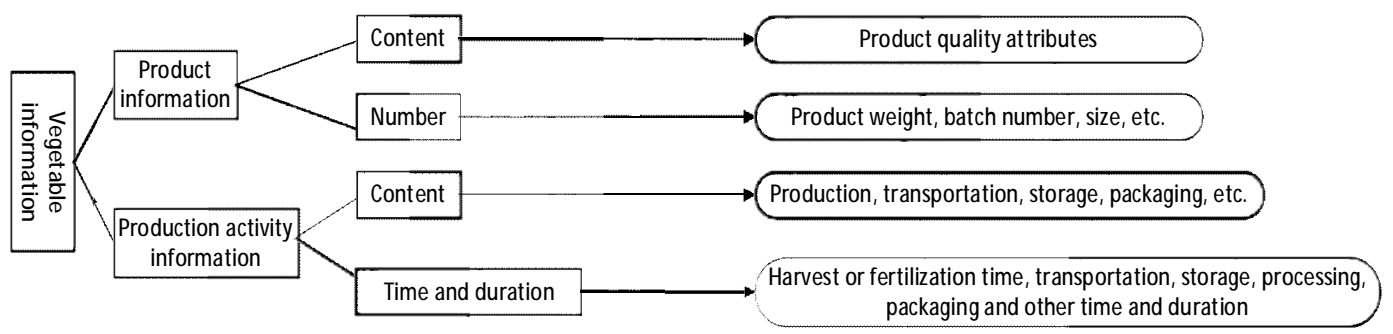

Fig. 1 Basic structure of vegetable quality and safety information

\section{Design of Vegetable information release system}

In this paper, we will establish the automatic vegetable summarization system from the information of the three stages of the growth stage. Consumers can be found in the details of each vegetable through the system. The system allows the consumer to find detailed information about each vegetable and to evaluate the state of the vegetables and the service status of the salesperson after the consumers have purchased the vegetables. According to the consumer feedback, the system manager 
can improve and upgrade the system, producers carry out their production ${ }^{[3]}$. The whole idea is shown in Fig.2

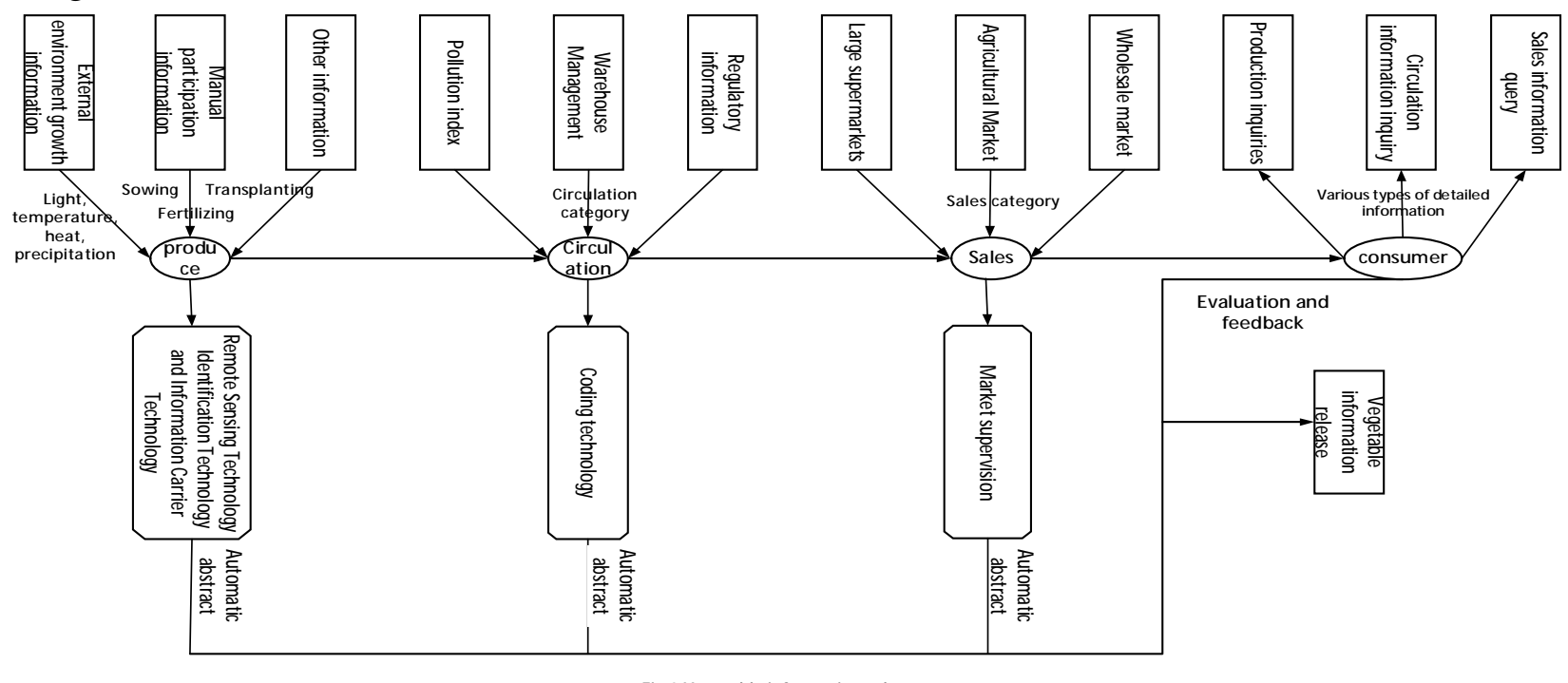

\section{Milestone records of vegetable}

External environment information. Most vegetables are produced in an open environment and will be affected by the surrounding environment (eg, light, temperature, heat, precipitation, local pests). Therefore, the quality of agricultural production has to consider the impact of the surrounding environment ${ }^{[4]}$. Information on the environmental conditions of growing vegetables can be obtained from historical data on the local climate. Based on this information, we develop a corresponding external standard for vegetables and provide the basis for the model.

Information on human participation. From the selection, cultivation, fertilization, watering, each process requires the participation of people. Vegetable growth cycle, light duration, temperature control, fertilization, sowing soil selection, fertilization of the growth node and so are subject to human control. At the same time, it is very important to increase the information feedback in the process of vegetable artificial participation, which is very important for the post-vegetable information release.

Other information. In addition to external environmental information and human participation information, there are some other information needs to be collected and processed in the production phase of vegetables. The government's quality inspection departments supervise and audit the information of the vegetable production land, process information, purchase information for the vendors, and issue laws and regulations, as well as the management of quality control personnel. Those information are helpful to the establishment of the feedback model of vegetable fingerprint information.

Examples Marking of information data. The development of modern information technology has brought the possibility of retrospective quality. Quality-traceable implementation must be supported by modern information technology. The key information technologies that can be traced back to the quality of vegetables include: database technology, coding technology, electronic technology.

Transport phase. At present, it is far distance between the production and marketing of some vegetables. In order to maintain fresh vegetable surface, in the course of transportation, these vegetables may be added in excess of preservative. These so-called preservatives which is a hormone, harmful to the human body. Therefore, in the process of transportation, the information feedback of preservative is very important to enhance the trust of consumers and enhance the value of vegetables.

Vegetable storage management. Vegetables from the production to consumers, and the transport business is not directly from the origin of the vegetables pulled to sell. They are usually from the 
hands of farmers to buy vegetables, first transferred to the warehouse. They are based on local demand and freight conditions will be shipped to all over the vegetables. Therefore, a warehouse will often have hundreds of vegetables. Temperature, humidity, ventilation, lighting and other information in the warehouse for fresh vegetables are very important. Enhance the storage of information stored in the warehouse of information disclosure, is the construction of vegetable quality feedback system is an indispensable link.

Supervision information. When listing facts use either the style tag List signs or the style tag List numbers. The whole process of vegetable transportation is under the supervision of the supervision department. Prior to the regulatory information is not easy to obtain, and an effective information feedback system can not be separated from the government's guidance and support. Disclosure of regulatory information from government agencies can help to gain further consumer confidence and enhance the value of fresh vegetables. The transportation process is the last barrier of the agricultural products entering the consumption field. The quality and safety of the agricultural products in the process of circulation is of great significance, and the testing plays an important role in technical support.

Two - dimensional code technology. Two-dimensional code is one-dimensional code based on the extension of the two directions on the encoding and decoding, coding capacity than one-dimensional code, the scope of application than one-dimensional code to be wide, with the ability to repair errors. It can describe the black-and-white graphs which are distributed in a plane (two-dimensional direction) according to certain rules, and record the data information.

Examples A Feedback Model of Consumer information. Consumers are in the final layer of the vegetable information feedback chain, but have a decisive power for producers, transporters and sellers. Consumers can obtain the production information, transportation information and sales information of a certain vegetable by scanning code technology, and according to the actual eating effect evaluation. In addition, the system managers can be based on consumer feedback information to improve the model to make the model more realistic and more practical functions.

\section{Automatic Summary Information Acquisition Technology}

Although the collection of data is an extremely complex process, the milestone record of vegetables provides a wealth of data, combined with the authoritative department of the standard reference model comparison. Through the calculation of a score and generate evaluation, the final automatic generation of abstracts so as to lay the foundation for the information dissemination model ${ }^{[5]}$. As shown in Fig.3

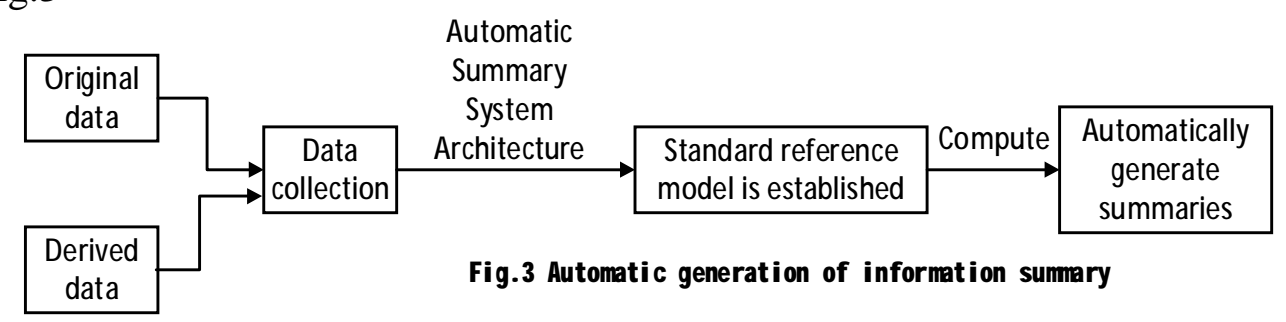

\section{Model Realization and Prospect}

The circulation of agricultural products related to the people's livelihood, including the basket project, including many of the benefits of the policy has been the Government and the relevant departments to focus on and strive to solve the problem. The establishment of vegetable information release model, to achieve the value of vegetables to enhance the better but also to traceable purposes, but also on the development of China's agricultural products plays a huge role in promoting. To achieve this process, is conducive to improving the market information services. China has established and developed a number of agricultural information service system, mainly from the agricultural market access to the latest information, screening, processing, processing, and then set up a set of vegetable information query system. 
Release information flow. Formation needs to be reviewed, to meet the requirements of the product can be a comprehensive listing. Consumers buy products in the market to evaluate the actual function. System model is in Fig.4

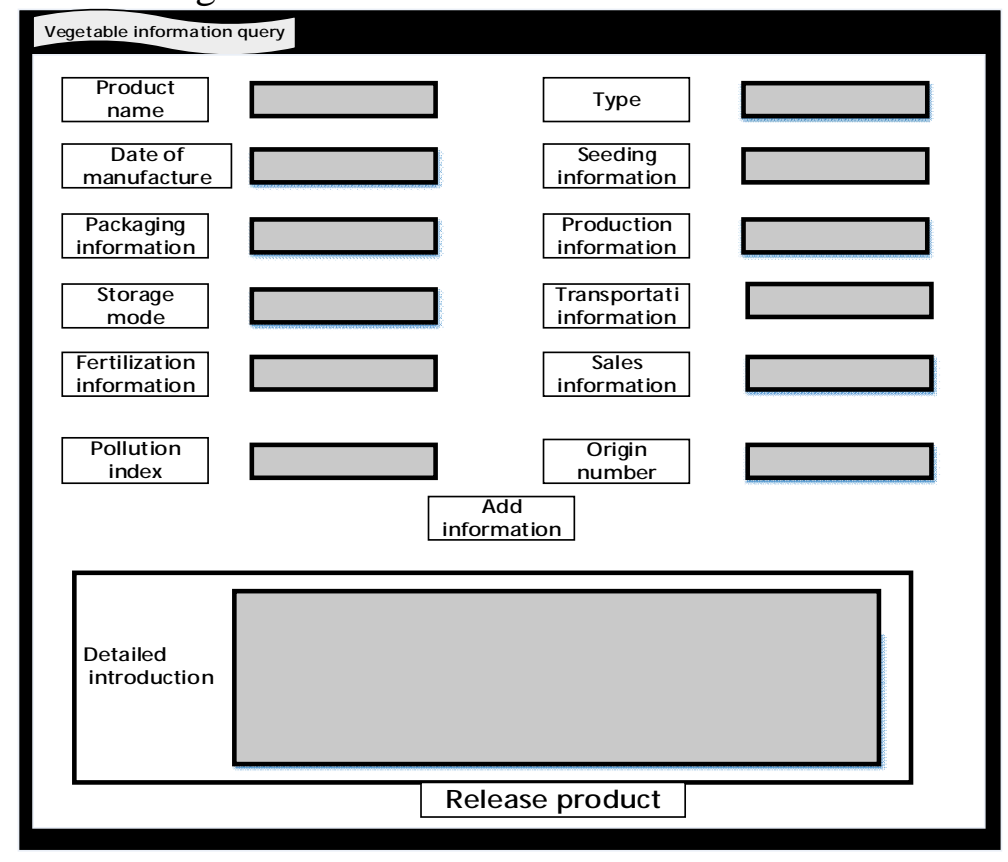

Fig.4 Vegetable information query

Information dissemination platform. E-commerce website can be used as information publishing front, all kinds of information integration, publishing, and other agricultural market information networking. In addition, e-commerce site can provide all kinds of information value-added services, such as information search, query, sales of similar products, prices, summary, comparison $^{[6]}$. These features help users to reduce the cost of information search, improve the utilization of information and safety standards for agricultural products ${ }^{[7]}$. The product information includes product name, type, production date, fertilizer information, sowing information, packing information, storage method, transportation information, sales information, Number, picking information so that people achieve the value of vegetables and purpose of traceability.

\section{Acknowledgements}

This research is supported by National Science Foundation of China (Grant No. 71203162), Science and Technology Planning Project of Guangdong Province, China (Grant No. 2014B040404072), Natural Science Foundation of Guangdong Province, China (Grant No. 2015A030313642), and Innovation Project of Wuyi University (Grant No. 2014KTSCX128 and 2015KTSCX144).

\section{Reference}

[1] Parreno-Marchante A, Alvarez-Melcon A, Trebar M, et al. Advanced traceability system in aquaculture supply chain[J].Journal of Food Engineering,2014,122:99-109.

[2] Nicoloso C S, Silveira V CP,Rosa J S,et al.Costs and return of investment or beef cattle traceability in a full cycle system Production in the state of Rio Grande do Sul, Brazil[C].Asociaction Interprofesional para el Desarrollo Agrario,2013,pp:35-46.

[3] Atef W Idriss,Mohammad S EI-Habbab.Middle East food safety perspectives[J].Journal of Science of Food and Agriculture, 2014, 94(10):1922-1927.

[4] Iyengar V.Food safety measurement issues:way forward [J].Journal of Radioanalytical and Nuclear Chemistry,2013, 297(3):451-455. 
[5] Bai Guangzu, He Yuanbiao, Ma Jianxia, etal. Application of Machine Learning with Limited Corpus to Identify Structure of Scientific Abstracts Automatically [J]. New Technology of Library and Information Service, 2014.

[6] Rouviere E, Latouche KI mpact of liability rules on modes of coordination for food safety in supply chains[J].European Journal of Law Econ,2014, 37(1):111-130.

[7] Shin Jongmin, Jenon Byeong chan, Yang Dongmin. Multiple RFID tags identification with mary query tree Scheme[J].IEEE Communications Letters,2013,17(3):604-607. 